\title{
Modeling of bond between near-surface mounted CFRP laminate strips and concrete
}

\author{
José Sena Cruz *, Joaquim Barros \\ Department of Civil Engineering, University of Minho, Azurém, 4800-058 Guimarães, Portugal \\ Received 10 March 2004; accepted 12 March 2004 \\ Available online 20 May 2004
}

\begin{abstract}
Near-surface mounted (NSM) laminate strips of carbon fiber reinforced polymer (CFRP) is a promising technique for increasing the flexural and the shear strength of deficient concrete members. Using the results of an experimental program with pullout-bending tests and developing a numerical strategy, an analytical bond stress-slip relationship was obtained. This relationship was converted into a bond stress-slip constitutive law for a line interface finite element, used to simulate the concrete-CFRP bond behavior. The numerical model developed predicted all the significant aspects registered experimentally, and can be used to assess relevant information in the design of concrete structures strengthened by NSM technique.
\end{abstract}

(c) 2004 Elsevier Ltd. All rights reserved.

Keywords: Bond; Slip; Near-surface mounted; CFRP laminate strip; Epoxy-adhesive; Line interface element

\section{Introduction}

In last years, a strengthening technique based on the near-surface mounted (NSM) of laminate strips of carbon fiber reinforced polymer (NSM CFRP) has been used to increase the load bearing capacity of concrete members. The term 'near' is used to differentiate this technique of structural strengthening from that using externally-bonded FRP composites (EBR). In the NSM CFRP technique, laminate strips of CFRP are introduced into grooves pre-cut on the concrete cover of the elements to be strengthened that were previously filled with epoxy-adhesive. The CFRP has a cross-section of about $1.4 \mathrm{~mm}$ thick and $10 \mathrm{~mm}$ width, while the width and the depth of the groove vary between 3 and $5 \mathrm{~mm}$, and $12-15 \mathrm{~mm}$, respectively. Instead of laminate strips some researchers have used FRP bars (manufactured

\footnotetext{
${ }^{*}$ Corresponding author. Tel.: +351-253-510-200; fax: +351253-510-217.

E-mail address: jsena@civil.uminho.pt (J.S. Cruz).
}

using a thermosetting resin reinforced with glass or carbon fibers) but, in these cases, the grooves have larger dimensions [1-5].

To assess the efficiency of the NSM CFRP technique for elements failed by shear, the behavior of beams strengthened according to the NSM CFRP technique was compared to the behavior of beams strengthened by two other techniques: using conventional stirrups; applying strips of CFRP sheet. The first one was the most effective, easiest and fastest to apply [6]. This effectiveness was not only in terms of the beam load bearing capacity, but also in terms of the ductility of the beam's behavior.

The efficacy of the NSM CFRP technique was also evaluated in concrete columns [7] and concrete beams [8] failed by bending. Maximum CFRP strain values near CFRP ultimate strain were registered, indicating that NSM CFRP is a very effective technique for this type of concrete elements. However, in concrete elements reinforced with high percentage of conventional steel bars, premature failure of the concrete cover can compromise this effectiveness [9]. To understand the complex 
phenomena involved in this type of failure the behavior of the CFRP-concrete bonding must be assessed.

For this purpose, pullout-bending tests were carried out [10], having been measured the pullout force at the CFRP, and the slip at the free and loaded ends. The influence of the concrete strength and bond length on the CFRP-concrete bonding behavior was analyzed. To define a local bond stress-slip relationship, $\tau-s$, a numerical strategy was developed where the experimental results were taken into account.

Based on the methodology used on the bonding of steel bars to concrete, several approaches have been developed to establish a local $\tau-s$ relationship for FRP rods [11-15]. The method proposed by Focacci et al. [14] was used in the present work, with the necessary adjustments to account the specificities of the present strengthening technique.

The finite element method (FEM) is a powerful tool to simulate the behavior of reinforced concrete structures [16]. Interface elements are adjusted for modeling the bond between concrete and reinforcement [17-19]. However, they have been rarely used in the simulation of the FRP-concrete bonding [20,21]. In the present paper, the $\tau-S$ relationship obtained from the analytical method was used to define the tangential component of the constitutive law of a line interface element applied in the simulation of the pullout-bending tests carried out. The performance of this numerical modeling is analyzed.

\section{Analytical modeling of bond between CFRP and concrete}

\subsection{Bond stress-slip expression}

Assuming that CFRP has a linear-elastic behavior and neglecting the thickness of this composite material, the equilibrium of a CFRP of length $\mathrm{d} x$ bonded to concrete can be given by the following expression (see Figs. 1 and 2):

$$
\tau(x)=\frac{E_{\mathrm{f}} t_{\mathrm{f}}}{2} \frac{\mathrm{d} \varepsilon_{\mathrm{f}}}{\mathrm{d} x}
$$

where $\tau(x)$ is the bond stress acting on the contact surface between CFRP and epoxy-adhesive, and $E_{\mathrm{f}}, t_{\mathrm{f}}$ and $\varepsilon_{\mathrm{f}}$ are the Young's modulus, the thickness and the strain of the CFRP, respectively.

In a representative region of the CFRP-adhesiveconcrete bonding, the strain components indicated in Fig. 3 are presented. Neglecting the concrete and the adhesive deformability in the slip evaluation, the CFRP strain can be obtained from the slip variation, $\mathrm{d} s$ :

$\varepsilon_{\mathrm{f}}=\frac{\mathrm{d} s}{\mathrm{~d} x}$

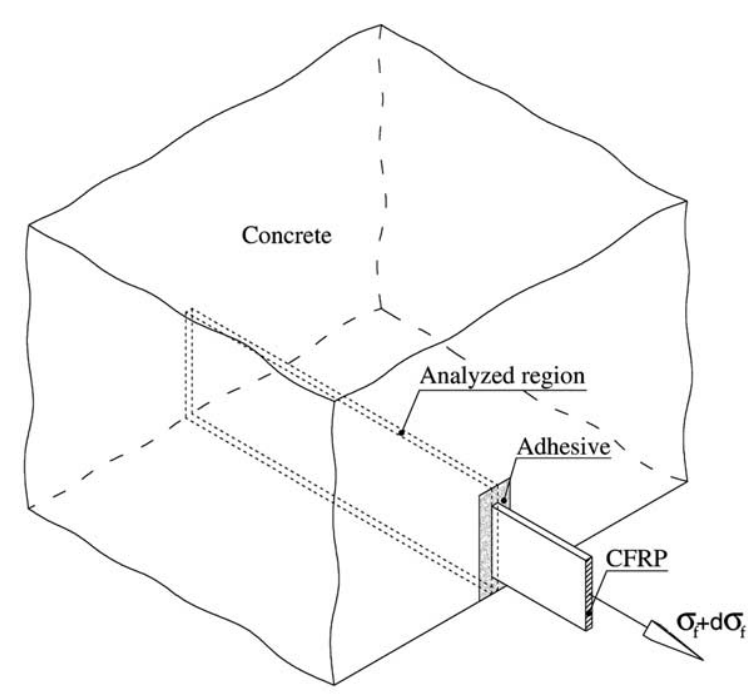

Fig. 1. Region of interest in the analysis.

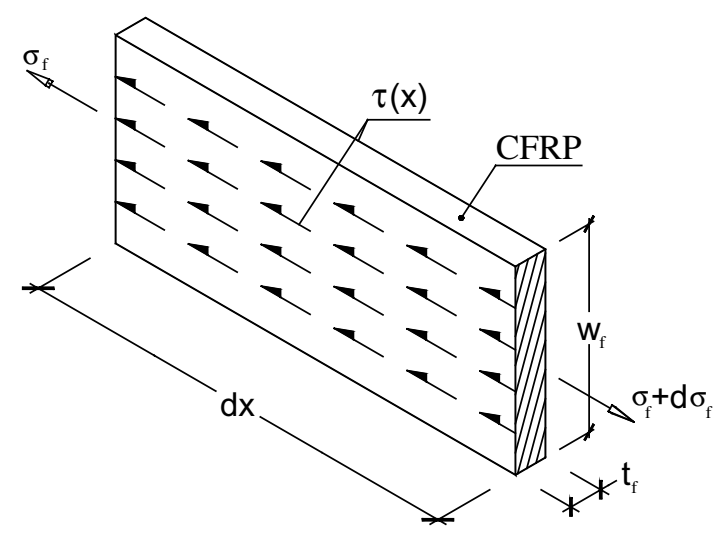

Fig. 2. Equilibrium of the CFRP.

Replacing (2) into (1), the differential equation that governs the slip of CFRP bonded into concrete is derived:

$\frac{\mathrm{d}^{2} s}{\mathrm{~d} x^{2}}=\frac{2}{t_{\mathrm{f}} E_{\mathrm{f}}} \tau(s)$

Based on expressions similar to this one, important phenomenon's of concrete behavior, like reinforcement anchorage length, tension-stiffening, crack spacing and crack opening, can be simulated. The quality of the local bond stress-slip relationship, $\tau(s)$, has decisive importance on the accuracy of this simulation.

In the present work the local bond stress-slip relationship is composed by the following two equations: 


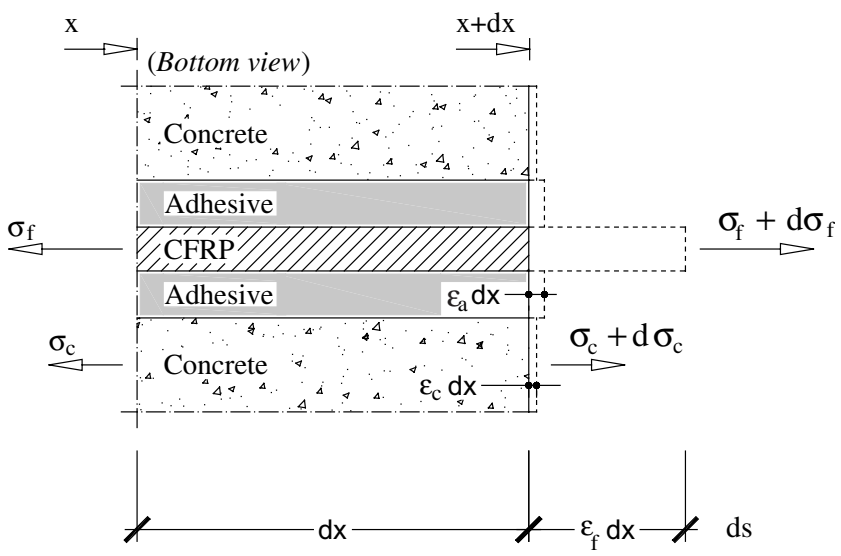

Fig. 3. Strain of the intervening materials of the bond region.

$\tau(s)= \begin{cases}\tau_{m} \times\left(\frac{s}{s_{m}}\right)^{\alpha} & \text { if } s \leqslant s_{m} \\ \tau_{m} \times\left(\frac{s}{s_{m}}\right)^{-\alpha^{\prime}} & \text { if } s>s_{m}\end{cases}$

where $\tau_{m}$ and $s_{m}$ are the bond strength and its corresponding slip, and $\alpha$ and $\alpha^{\prime}$ are parameters defining the shape of the curves. Eq. (4) for $s \leqslant s_{m}$ was used by Eligehausen et al. [22] and defines the bond behavior up to peak stress (ascending branch). Eq. (4) for $s>s_{m}$ was adopted by De Lorenzis et al. [15] and reproduces the post-peak bond behavior (descending branch). This law was selected due to its simplicity and ability to simulate the phenomena under discussion.

As the adhesive deformability was neglected in the present approach, the $s_{m}$ parameter should increase with the bond length. To obtain a 'real' local $\tau(s)$ relationship, the experimental test set up would be conceived such as the CFRP-adhesive slip, the concrete-adhesive slip and the adhesive deformability were registered independently, which is too difficult with the technologies available in the major part of the Laboratories.

\subsection{Numerical strategy}

Fig. 4 represents a CFRP fixed to concrete by epoxyadhesive on a bond length $L_{\mathrm{b}}$. If the CFRP is slipping due to a pullout force applied, $\bar{N}$, the slip, $s=s(x)$, the bond stress between CFRP and epoxy-adhesive, $\tau=\tau(x)$, the strain, $\varepsilon=\varepsilon_{\mathrm{f}}(x)$, and the axial force, $N=N(x)$, in the CFRP, along the bond length can be obtained. For the particular case of the bond length extremities, designated by loaded end and free end:

$x=0 \Rightarrow\left\{\begin{array}{l}s=s_{\mathrm{f}} \\ N=0 ; \quad x=L_{\mathrm{b}} \Rightarrow\left\{\begin{array}{l}s=s_{1} \\ N=\bar{N} \\ \varepsilon_{\mathrm{f}}=0\end{array} \varepsilon_{\mathrm{f}}=\bar{N} /\left(E_{\mathrm{f}} \times A_{\mathrm{f}}\right)\right.\end{array}\right.$

where $s_{\mathrm{f}}$ and $s_{1}$ are the slips at free and loaded ends, respectively. In the present work, numerical and experimental entities will be involved, having been differentiated by a strikeover on the experimental ones. For instance, $\bar{N}_{i}$ represents the pullout force experimentally measured in the $i$ th scan reading.

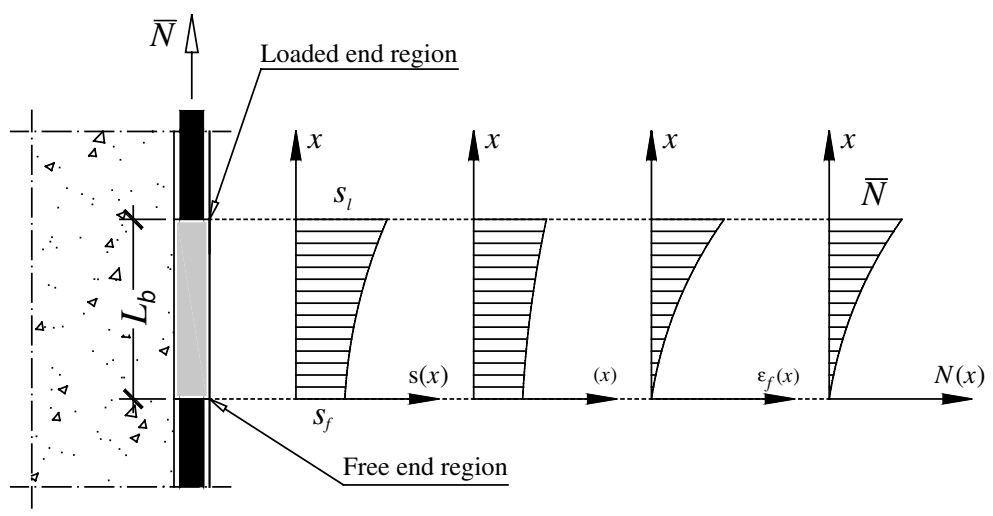

Fig. 4. Entities involved. 
From the pullout-bending tests carried out [10], the slip at the free end, $\bar{s}_{\mathrm{f}}$, the slip at the loaded end, $\bar{s}_{1}$, and the pullout force, $\bar{N}$, were obtained. For a generic scan reading $i$, the $\bar{s}_{\mathrm{f}}^{i}, \bar{s}_{1}^{i}$ and $\bar{N}_{i}$ were known. Using these experimental results, the purpose was to obtain the parameters $s_{m}, \tau_{m}, \alpha$ and $\alpha^{\prime}$ of Eq. (4) that fit the differential Eq. (3) as much as possible. To get such aim, a computational code was developed, based on the algorithm described in Fig. 5. In this algorithm the second order differential Eq. (3) was solved by the RungeKutta-Nyström (RKN) method [23]. The following main steps compose this algorithm:

- In the first step, fixing the parameters $s_{m}, \tau_{m}, \alpha$ and $\alpha^{\prime}$, the $\tau=\tau(s)$ relationship is defined.

- The maximum loaded end slip when the free end slip does not occur, $\tilde{s}_{1}$, is obtained (see Module A).

- For the experimental $i$ th scan reading, the free end slip, $\bar{s}_{\mathrm{f}}^{i}$, the loaded end slip, $\bar{s}_{1}^{i}$, and the pullout force, $\bar{N}_{i}$ are read.
- Taking the free end slip, $\bar{s}_{\mathrm{f}}^{i}$, and using Eq. (3), the numerical pullout force at the loaded end, $N_{i}\left(\bar{s}_{\mathrm{f}}^{i}\right)$, is calculated (see Module B).

- The error associated to $N_{i}\left(\bar{s}_{\mathrm{f}}^{i}\right)$ is calculated. This error is the difference, in absolute value, between the areas corresponding to the experimental and numerical curves. The points $\left(\bar{s}_{\mathrm{f}}^{i-1}, N_{i-1}\left(\bar{s}_{\mathrm{f}}^{i-1}\right)\right)$ and $\left(\bar{s}_{\mathrm{f}}^{i}, N_{i}\left(\bar{s}_{\mathrm{f}}^{i}\right)\right)$ are used to define the numerical curve, while experimental curve is represented by points $\left(\bar{s}_{\mathrm{f}}^{i-1}, \bar{N}_{i-1}\right)$ and $\left(\bar{s}_{\mathrm{f}}^{i}, \bar{N}_{i}\right)$.

- Taking the loaded end slip, $\bar{s}_{1}^{i}$, and using Eq. (3) the pullout force at the loaded end, $N_{i}\left(\bar{s}_{1}^{i}\right)$, is evaluated. In this case the following two loaded end slip conditions should be considered: (i) if $\bar{s}_{1}^{i}<\tilde{s}_{1}$ the determination of $N_{i}\left(\bar{s}_{1}^{i}\right)$ must take into account that the effective bond length is less than $L_{\mathrm{b}}$ (see Module C); (ii) if $\bar{s}_{1}^{i} \geqslant \tilde{s}_{1}$ the evaluation of $N_{i}\left(\bar{s}_{1}^{i}\right)$ is based on the Module D.

- The error associated to $N_{i}\left(\bar{s}_{1}^{i}\right)$ is calculated. This error is the difference, in absolute value, between the areas

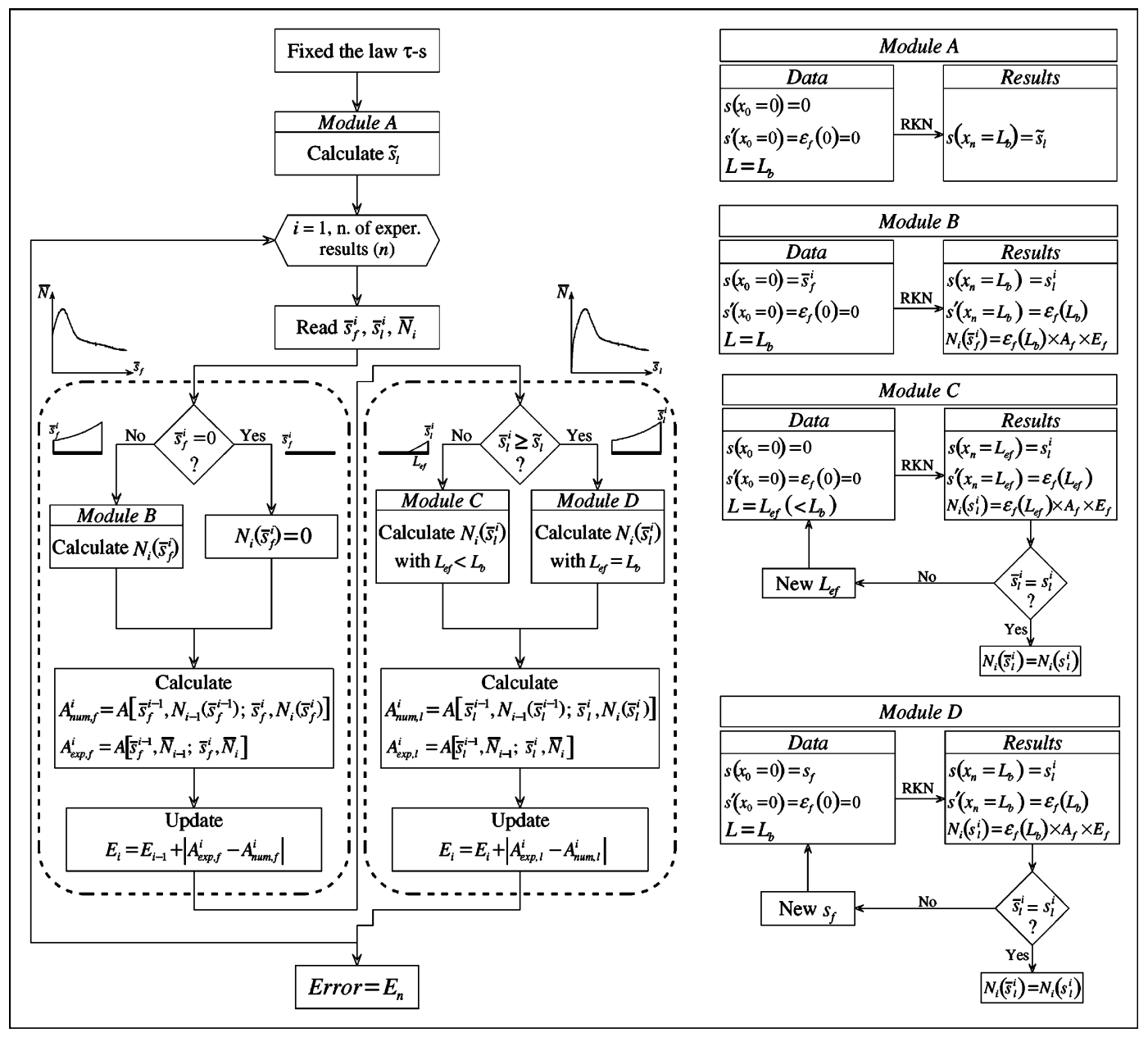

Fig. 5. Algorithm implemented. 
corresponding to the experimental and numerical curves. The points $\left(\bar{s}_{1}^{i-1}, N_{i-1}\left(\bar{s}_{1}^{i-1}\right)\right)$ and $\left(\bar{s}_{1}^{i}, N_{i}\left(\bar{s}_{1}^{i}\right)\right)$ are used to define the numerical curve, while experimental curve is represented by points $\left(\bar{s}_{1}^{i-1}, \bar{N}_{i-1}\right)$ and $\left(\bar{s}_{1}^{i}, \bar{N}_{i}\right)$.

In the Modules $C$ and $D$ an iterative procedure is required, having been used the successive bisection method.

\subsection{Example}

Beam B2_fcm45_Lb80 of the pullout-bending tests carried out by Sena-Cruz and Barros [10] was selected to exemplify the application of the method described in the last section. The average concrete compression strength $(\mathrm{fcm})$ and the bond length (Lb) of this specimen were 45 $\mathrm{MPa}$ and $80 \mathrm{~mm}$, respectively. The CFRP had $t_{\mathrm{f}}=1.39$ $\mathrm{mm}$ and $E_{\mathrm{f}}=160 \mathrm{GPa}$.

To assure that peak pullout force and its corresponding slip obtained numerically are similar (less than a tolerance of $1 \%$ ) to the values registered experimentally, the following method was used:

Step 1: fixing the parameters $\alpha$ and $\alpha^{\prime}$, the values of $s_{m}$ and $\tau_{m}$ of the best fitting were found;

Step 2: using the values of $s_{m}$ and $\tau_{m}$ obtained in the previous step, the values of $\alpha$ and $\alpha^{\prime}$ giving the best fitting were determined.

To assure the tolerance imposed, an iterative procedure in these steps was implemented. The good performance of the method developed is well demonstrated in Fig. 6, where the experimental and the numerical slippullout force relationship are compared. At the peak pullout load the variation of the slip, bond stress and axial force along the bond length is shown in Fig. 7. At this loading phase the bond behavior is essentially nonlinear, and half of the bond length is in the softening regime.

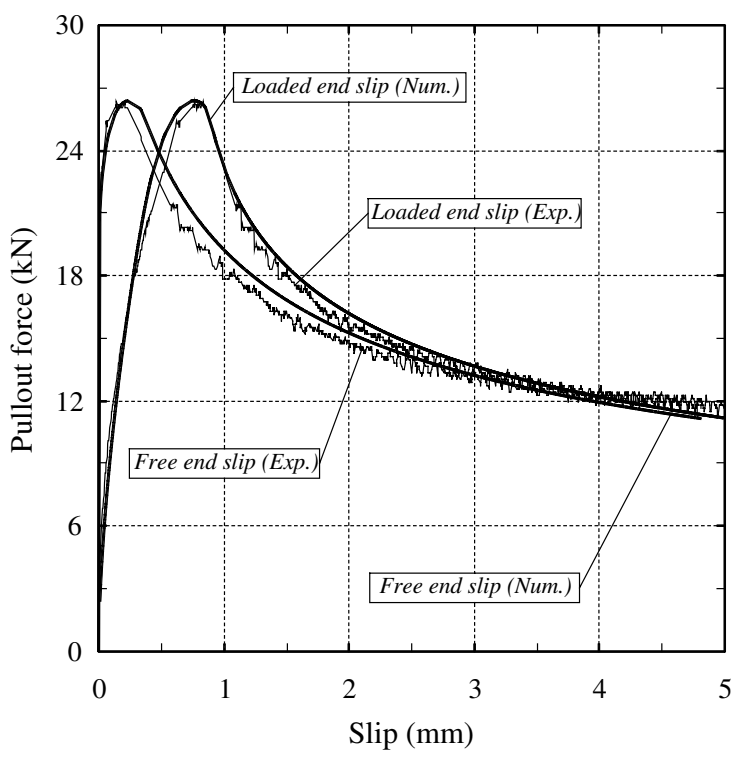

Fig. 6. Simulation of specimen B2_fcm45_Lb80.

\subsection{Local bond stress-slip law for NSM CFRP technique}

Using the results obtained in the experimental program [10], the parameters $s_{m}, \tau_{m}, \alpha$ and $\alpha^{\prime}$ of the local bond stress-slip law (see Eq.(4)) were found using the numerical strategy described in Section 2.2 and applied in Section 2.3. For each series (composed by three specimens), the average relationship between the loaded end slip and the pullout force was used to calibrate the law.

Fig. 8 shows that the loaded end slip vs. pullout force relationship obtained analytically (thick line) fits quite well the corresponding experimental envelop (hatch). Similar performance was registered in the remainder series.

The values of the parameter's law and the error obtained in each analysis are included in Table 1. The error

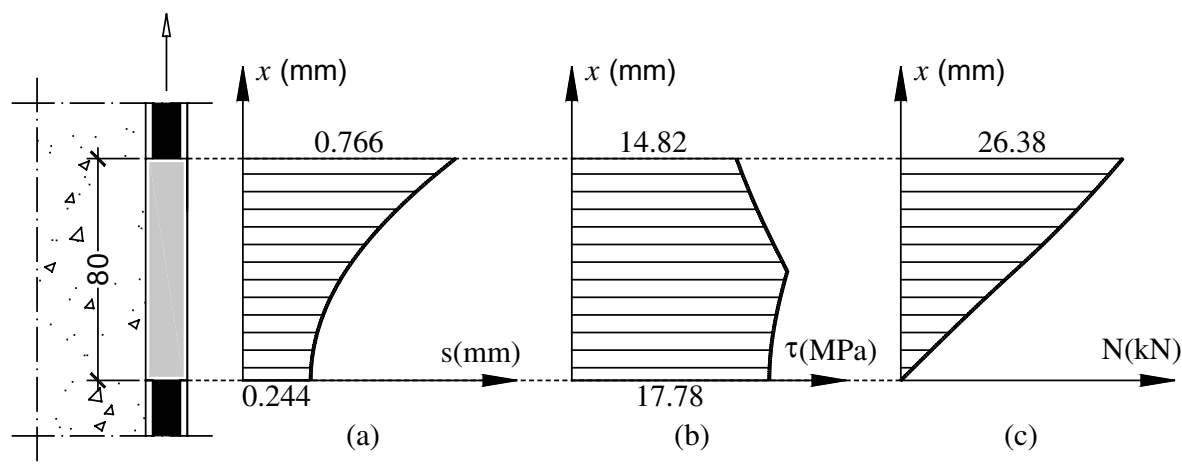

Fig. 7. Variation of the slip (a), bond stress (b) and axial force (c) along the bond length of specimen B2_fcm45_Lb80. 

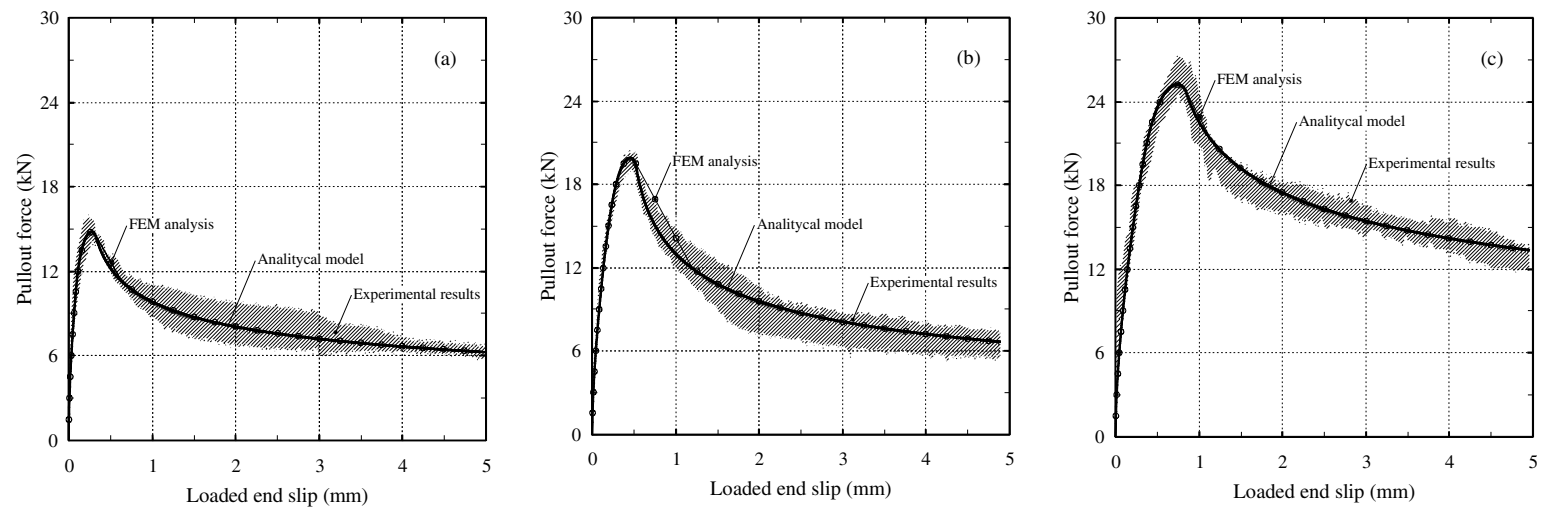

Fig. 8. Numerical and experimental results of series_fcm35_Lb40 (a),_fcm45_Lb60 (b) and_fcm70_Lb80 (c).

Table 1

Values of the parameters defining the local bond stress-slip relationship

\begin{tabular}{llllll}
\hline Series & $s_{m}(\mathrm{~mm})$ & $\tau_{m}(\mathrm{MPa})$ & $\alpha$ & $\alpha^{\prime}$ & Error $(\%)$ \\
\hline _fcm35_Lb40 & 0.180 & 20.60 & 0.13 & -0.27 & 2.04 \\
_fcm35_Lb60 & 0.228 & 20.68 & 0.19 & -0.35 & 5.92 \\
_fcm35_Lb80 & 0.290 & 18.90 & 0.17 & -0.33 & 6.96 \\
_fcm45_Lb40 & 0.144 & 21.40 & 0.21 & -0.23 & 4.66 \\
_fcm45_Lb60 & 0.231 & 19.50 & 0.24 & -0.39 & 2.98 \\
-fcm45_Lb80 & 0.430 & 19.50 & 0.35 & -0.45 & 2.75 \\
_fcm70_Lb40 & 0.189 & 21.50 & 0.24 & -0.29 & 3.37 \\
_fcm70_Lb60 & 0.210 & 18.00 & 0.21 & -0.29 & 2.36 \\
-fcm70_Lb80 & 0.345 & 18.20 & 0.19 & -0.27 & - \\
Average & 0.250 & 19.81 & 0.21 & -0.32 & - \\
CV & & & 21.49 & \\
\hline
\end{tabular}

${ }^{\mathrm{a}}$ Coefficient of variation.

is the difference, in absolute value, between the areas corresponding to the experimental and analytical curves. From these data the following observations can be pointed out:

- The error of each series is quite acceptable.

- A reasonable coefficient of variation was obtained in the bond strength.

- Large scatter in the values of $s_{m}, \alpha$ and $\alpha^{\prime}$ was obtained.

- $s_{m}$ increases with the bond length due to the reasons pointed out in Section 2.1.

\section{FEM modeling of bond between CFRP and concrete}

Under the finite element framework the bond behavior between concrete and reinforcing systems is usually simulated by interface elements $[18,19]$. A line interface element was implemented in the FEMIX computer code where several types of elements and nonlinear material models can be selected to simulate the behavior of reinforced concrete structures [24]. The pullout-bending test was considered a plane stress problem. The finite element mesh of half specimen is represented in Fig. 9. Four-node serendipity plane stress elements with $2 \times 2 \mathrm{G}$ integration scheme were used to simulate the concrete beam and the steel hinge. The CFRP was simulated by $2 \mathrm{D}$ frame elements. Linear elastic behavior was assumed for these materials, having their properties been taken from the experimental program. To connect the CFRP to concrete, four-node line interface elements with two-point Lobatto integration rule were used. The bond stress-slip relationship obtained in previous section was used to model the tangential stiffness of the interface element. As CFRP laminate strip has smooth surfaces and epoxy-adhesive has low Young's modulus (in comparison to concrete and CFRP), the normal stiffness of the interface element has marginal effect on the bonding behavior of CFRPconcrete, having been attributed a constant value of $1 \mathrm{e}+06 \mathrm{~N} / \mathrm{mm}^{3}$. The load was applied by direct dis- 


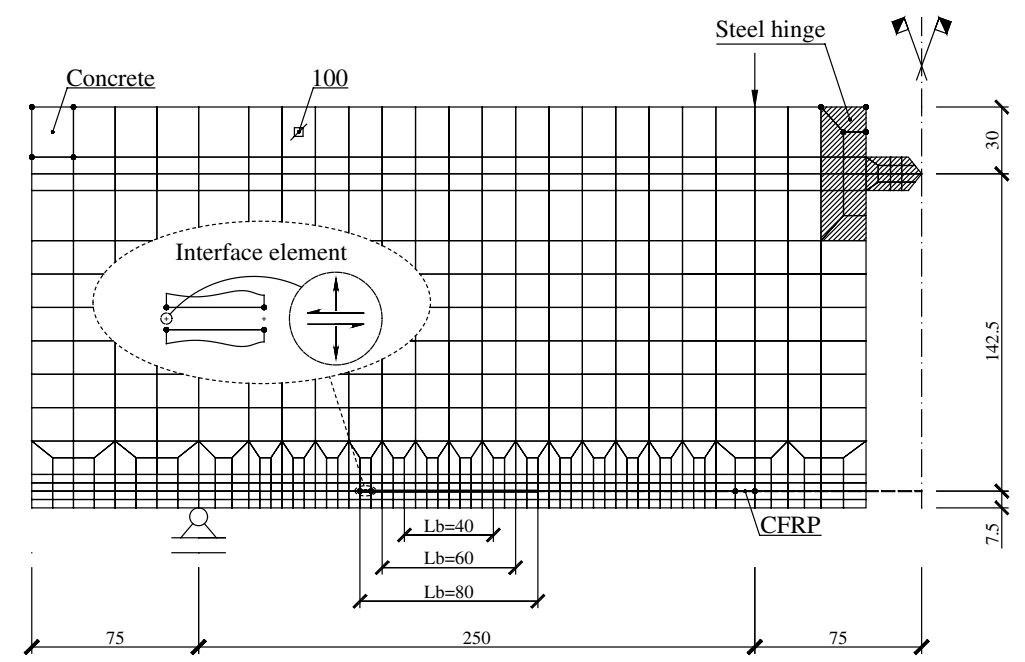

Fig. 9. Finite element idealization.

placement-control at loaded point. The properties for the tangential stiffness of the interface element were taken from Table 1. The relationship between the pullout force and the loaded end slip obtained numerically is compared in Fig. 8 with the results determined analytically and registered experimentally. The good agreement observed is extensive to all the specimens of the experimental program. Due to abrupt load decay just after peak load, some numerical difficulties occurred in this phase, where a deviation between numerical and analytical approaches is perceptible. This deviation increases with the magnitude of the load decay. The use of the arc-length method with the controlling displacement at loaded end slip will overcome this deficiency [18], but the computer code used has not yet this numerical facility.

\section{Anchorage length}

Due to safety and economical reasons, the anchorage length $L_{\text {an }}$ of the CFRP should be evaluated for accomplishing the requisites imposed by service and ultimate limit state analysis, i.e.:

$L_{\mathrm{an}}=\max \left\{L_{\mathrm{an}, \mathrm{S}}, L_{\mathrm{an}, \mathrm{U}}\right\}$

where $L_{\mathrm{an}, \mathrm{S}}$ and $L_{\mathrm{an}, \mathrm{U}}$ are the anchorage length at service and ultimate limit states, respectively. To determine the anchorage length, the local bond stress-slip relationship should be known. In the present analysis the average values of $\tau_{m}, \alpha$ and $\alpha^{\prime}$ were used (see Table 1). For the bond lengths considered in the carried out experimental program, a linear increasing trend between $s_{m}$ and $L_{\mathrm{b}}$ was observed, but experimental research should be done with larger bond lengths to establish more general relationship. While no more extensive experimental data are available, a linear relationship $s_{m}=0.0042 \times L_{\mathrm{b}}$ is assumed.

At service limit state it is desired that the free end does not slip [14,15], consequently, the pullout force at the onset of free end slip is of practical interest. According to the method described in Section 2.2 this pullout force corresponds to $N\left(\tilde{s}_{1}\right)$. Fig. 10 includes the $N\left(\tilde{s}_{1}\right)$ and $\tilde{s}_{1}$ as a function of the bond length. The experimental results are also included (donuts). Using this diagram, it is possible to find the bond length, $L_{\mathrm{an}, \mathrm{S}}$, for a given pullout service load. Due to the linear relationship between $s_{m}$ and $L_{\mathrm{b}}$ assumed in the present

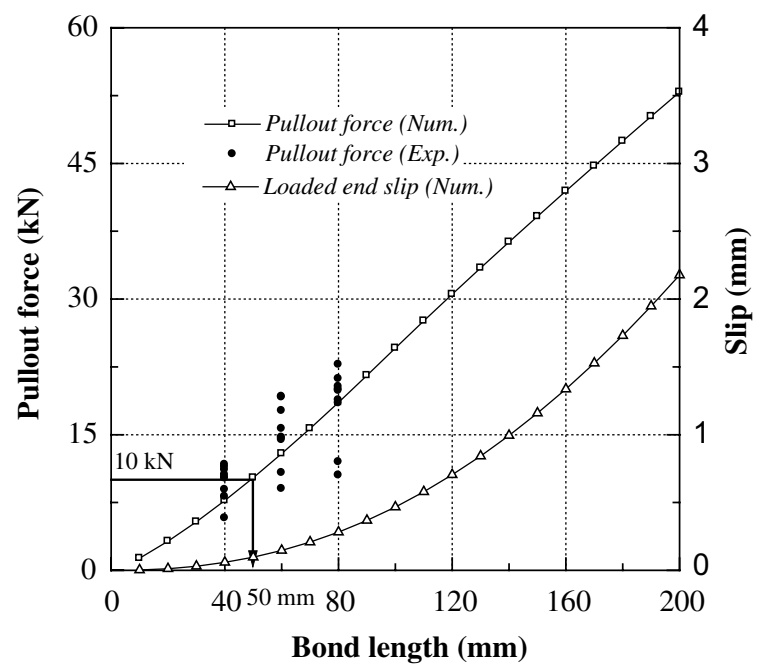

Fig. 10. Pullout force at the onset of free end slip, $N\left(\tilde{s}_{1}\right)$, and the loaded end slip, $\tilde{s}_{1}$, function of the bond length. 


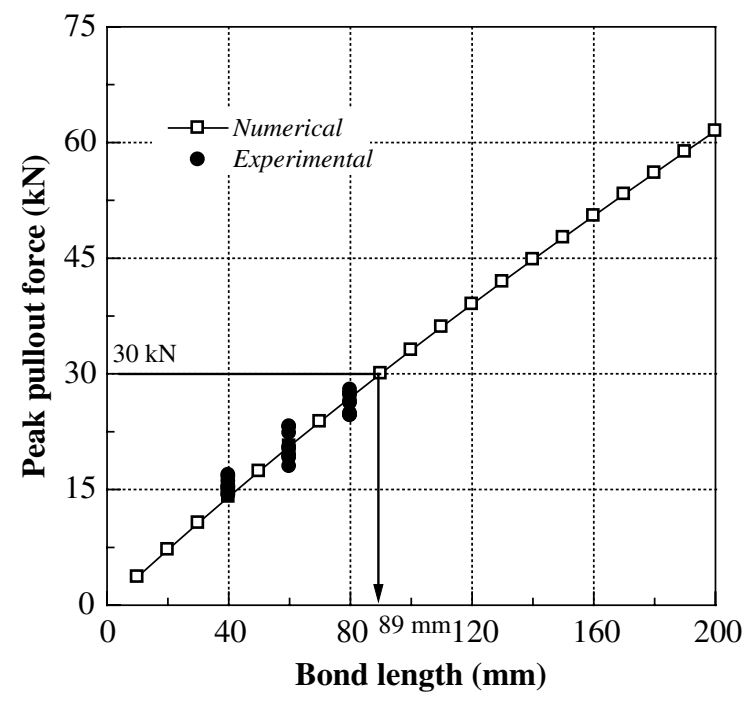

Fig. 11. Relationship between the peak pullout force and the bond length.

approach, this graph shows a more pronounced linear trend than the one observed in other works $[15,25]$.

To predict the peak pullout force, the entire bond stress-slip relationship should be known (see Fig. 7). Fig. 11 relates the peak pullout force with the bond length, that can be used to determinate the $L_{\mathrm{an}, \mathrm{U}}$ for a pullout force obtained in a ultimate limit state analysis. The numerical results fit the experimental ones with good accuracy.

As a design example, consider the case where a CFRP strip is submitted to 10 and $30 \mathrm{kN}$ for the service and ultimate limit state analysis, respectively. Using the charts represented in Figs. 10 and 11 the anchorage length needed is equal to 50 and $89 \mathrm{~mm}$ to accomplish the service and ultimate limit state requirements, respectively, being the anchorage length conditioned by the ultimate limit state analysis.

\section{Conclusions}

A research was developed to calibrate the parameters that define a local bond stress-slip relationship $(\tau-s)$ able to reproduce the pre- and the post-peak bond stress phases of the bonding between concrete and laminate strips of carbon fiber reinforced polymer (CFRP) in a near-surface mounted (NSM) strengthening technique. The research involved data obtained in experimental tests and a numerical strategy developed to solve the second-order differential equation that governs the slip phenomenon. The analytical method developed is also useful to evaluate the anchorage length of the CFRP at service and ultimate limit state analysis. Due to limita- tions on the experimental test facilities, the deformability of the epoxy-adhesive was not measured resulting a $\tau-S$ relationship that is dependent on the slip at peak bond stress. To use this relationship in the design practice the influence of the bond length and the thickness of the epoxy-adhesive should be assessed by experimental research.

The $\tau-S$ relationship was used as the tangential component of the material constitutive law of an interface element applied in the modulation of the concreteCFRP bond behavior under the FEM framework. The performance of the numerical simulation of the pulloutbending tests revealed that the analytical and the numerical strategy developed were adjusted.

\section{Acknowledgements}

The first and second authors wish to acknowledge the grant SFRH/BD/3259/2000 and SFRH/BSAB/291/2002POCTI, respectively, provided by FCT and FSE.

\section{References}

[1] Alkhrdaji T, Nanni A, Chen G, Barker M. Upgrading the transportation infrastructure: Solid RC decks strengthened with FRP. Concrete Int 1999;21(10):37-41.

[2] De Lorenzis L, Nanni A, La Tegola A. Strengthening of reinforced concrete structures with near surface mounted FRP rods. In: Proceedings of the international meeting on composite materials, PLAST, Milan, Italy; May 9-11, 2000. p. 8 .

[3] Tinazzi D, Modena C, Nanni A. Strengthening of masonry assemblages with fiber reinforced polymer rods and laminates. In: Proceedings of the Advancing with Composites, Milan, Italy; 2000.

[4] Tumialan JG, Morbin A, Nanni A, Modena C. Shear strengthening of masonry walls with FRP composites. Composites 2001 Convention and Trade Show, Composites Fabricators Association, Tampa, FL, October 3-6, 2001. p. 6.

[5] Tumialan JG, Huang PC, Nanni A, Silva P. Strengthening of masonry walls by FRP structural repointing. In: Nonmetallic reinforcement for concrete structures-FRPRCS5, Cambridge, England, July 16-18, 2001. p. 1033-42.

[6] Barros JAO, Dias SJE. Shear strengthening of reinforced concrete beams with laminate strips of CFRP. In: Proceedings of the international conference CCC2003 composites in construction, Cosenza, Italy, 2003. p. 289-94.

[7] Ferreira DRSM. Pilares de Betão Armado Reforçados com Laminados de Fibras de Carbono (Reinforced concrete columns strengthened with CFRP laminates. MS Thesis. Civil Engineering Department, University of Minho, Portugal, 2000 [in Portuguese].

[8] Barros JAO, Fortes AS. Concrete beams reinforced with carbon laminates bonded into slits. In: Proceedings of $5^{\circ}$ 
congreso de métodos numéricos en ingeniería, Madrid, Spain, 2002. p. 16.

[9] Fortes AS, Barros JAO. Desempenho de três técnicas de reforço à flexão de vigas de betão armado com CFRP (Performance of three CFRP strengthening techniques for RC beams). In: Proceedings of the conference Betão estrutural 2002, Lisbon, November, 2002. p. 233-42 [in Portuguese].

[10] Sena-Cruz JM, Barros JAO. Bond behavior of carbon laminate strips into concrete by pullout-bending tests. In: Proceedings of the international symposium bond in concrete-from the research to standards, Budapest, Hungry, November 20-22, 2002. p. 614-21.

[11] Larralde J, Silva-Rodriguez R. Bond and slip of FRP rebars in concrete. ASCE J Mater Civil Engng 1993;5(1): $30-40$.

[12] Malvar L. Tensile and bond properties of GFRP reinforcing bars. ACI Mater J 1995;92(3):276-2985.

[13] Cosenza E, Manfredi G, Realfonzo R. Behavior and modeling of bond of FRP rebars to concrete. ASCE J Compos Construct 1997;1(2):40-51.

[14] Focacci F, Nanni A, Bakis CE. Local bond-slip relationship for FRP reinforcement in concrete. ASCE J Compos Construct 2000;4(1):24-31.

[15] De Lorenzis L, Rizzo A, La Tegola A. A modified pull-out test for bond of near-surface mounted FRP rods in concrete. Elsevier, Comopos Part B: Engng 2002;33(8): 589-603.

[16] Barros JAO, Figueiras JA. Model for the analysis of steel fibre reinforced concrete slabs of grade. Comput Struct 2001;79:97-106.
[17] FIB. Bond of reinforcement in concrete. State-of-art report prepared by Task Group Bond Models (former CEB Task Group 2.5) 2000. p. 426.

[18] Rots JG. Computational modeling of concrete fracture. PhD Thesis. Delft University of Technology. 1988.

[19] Schellekens JCJ. Computational strategies for composites structures. PhD Thesis. Delft University of Technology. 1992.

[20] Henriques AA, Costeira SP, Oliveira L. Computational modeling of the nonlinear behaviour of concrete structures strengthened by FRP. In: Proceedings of the International Conference Composites in Construction-CCC2001, October 2001. p. 629-34.

[21] De Lorenzis. Strengthening of RC structures with nearsurface mounted FRP rods. PhD Thesis. University of Lecce, Italy, 2002.

[22] Eligehausen R, Popov EP, Bertero VV. Local bond stressslip relationships of deformed bars under generalized excitations. Report No. 83/23, Environ. Engng. Res. Council, University of California, Berkeley, CA, 1983.

[23] Kreyszig E. Advanced engineering mathematics 1993. Berlin: John Wiley \& Sons; 1993.

[24] Azevedo AFM, Barros JAO, Sena-Cruz JM, Gouveia, AV. Software no ensino e no projecto de estruturas (The use of software in the structural design and research). III LusoMoçambicano Conference, Mozambique, August 19-21, 2003. p. 81-92 [in Portuguese].

[25] Cosenza E, Manfredi G, Realfonzo R. Development length of FRP straight rebars. Elsevier, Compos Part B: Engng 2002;33(7):493-504. 